\title{
Ethanol extraction of canola oil: Kinetics and effects of type of solvent and microwave-pretreatment ${ }^{\text {th }}$
}

\author{
Ramiro J. Sánchez ${ }^{1,2, *}$, María B. Fernández ${ }^{1,2,3, a}$ and Susana M. Nolasco ${ }^{1,4, a}$ \\ ${ }^{1}$ Núcleo TECSE, Facultad de Ingeniería, Universidad Nacional del Centro de la Provincia de Buenos Aires, Olavarría, Argentina \\ 2 CONICET, Consejo Nacional de Investigaciones Científicas y Técnicas, Ciudad Autónoma de Buenos Aires, Argentina \\ 3 CIFICEN, Universidad Nacional del Centro de la Provincia de Buenos Aires-CONICET-CIC, Tandil, Argentina \\ ${ }^{4}$ CIC, Comisión de Investigaciones Científicas de la Provincia de Buenos Aires, La Plata, Argentina
}

Received 9 April 2019 - Accepted 13 May 2019

\begin{abstract}
The phenomenon and kinetics of the ethanol extraction of canola oil from microwavepretreated seeds was studied using a Fick's diffusion model. The extraction was performed in a batch system at constant temperature (313-333 K) at different times (300-64 800 s); then the total solvent-free extracts (SFE) were washed with hexane, obtaining oil as a hexane-soluble fraction (HSE) along a hexane-insoluble fraction. The values of the fitted parameters were different from those obtained by hexane extraction, showing an influence of the solvent on the kinetic parameters. A comparison of SEM images of preextracted, post-extracted with ethanol and post-extracted with hexane meals showed a dilution of the structural matrix with ethanol, not observed in post-extraction samples with hexane. This would indicate that a microwave-pretreatment is not necessary for the ethanol extraction of canola oil under the studied conditions, although it is important for breaking seed structures to facilitate the conventional extraction with hexane.
\end{abstract}

Keywords: canola oil / ethanol / kinetics / microwave

Résumé - Extraction de l'huile de colza en utilisant l'éthanol comme solvant : cinétique et effets du solvant et du prétraitement par micro-ondes. L'extraction à l'éthanol de l'huile de colza à partir de graines pré-traitées par micro-ondes ont été étudiés à l'aide d'un modèle de diffusion de Fick. L'extraction a été effectuée dans un système discontinu à température constante (313-333 K) à différents temps d'extraction (300-64 800 s); puis les extraits débarrassés de solvant (solvent-free extracts, SFE) ont été re-extraits avec de l'hexane, permettant l'obtention d'une huile avec une fraction soluble dans l'hexane (hexane-soluble fraction, HSE) et une fraction insoluble dans l'hexane. Les valeurs des paramètres ajustés étaient différentes de celles obtenues par extraction à l'hexane, montrant une influence du solvant sur les cinétiques d'extraction. Une comparaison des images SEM (microscope électronique à balayage) des tourteaux avant et après extraction à l'éthanol, et après extraction à l'hexane, a montré une détexturation de la matrice avec de l'éthanol, non observée dans les échantillons après extraction à l'hexane. Cela indiquerait qu'un prétraitement aux micro-ondes n'est pas nécessaire pour l'extraction à l'éthanol de l'huile de colza dans les conditions étudiées, bien qu'il soit important de casser les structures des semences pour faciliter l'extraction classique à l'hexane.

Mots clés : huile de colza / éthanol / cinétique / chauffage micro-ondes

\footnotetext{
Contribution to the Topical Issue "Rapeseed / Colza"

*Correspondence: rajusaia27@gmail.com

a Present address: Avda del Valle 5737, B7400JWI, Olavarría, Buenos

Aires, Argentina.
} 


\section{Introduction}

Canola oil is a vegetable oil considered nutritionally balanced, with a good linoleic/linolenic acid ratio (2:1), and healthy due to its high content of phenolic compounds (6.3$18.4 \mathrm{mg} / \mathrm{g}$ in defatted meal; Kozlowska et al., 1990). In addition, the presence of canolol has been detected in the canola oil extracted from thermally-treated seeds (Koski et al., 2003; Wakamatsu et al., 2005).

The oil is obtained by pressing and/or solvent extraction processes. Traditionally the used solvent in the industry is hexane, since it is stable, and presents a high solubilizing power and a convenient boiling point that favors its recovery (Sicaire et al., 2015). Nevertheless, this solvent obtained from fossil fuels is highly flammable, and causing negative effects on health and the environment (Sánchez et al., 2018a, b). In addition, the meal obtained after the extraction must be desolventized for later use (protein concentrates, animal feed), a process that involves solvent losses and a high energy cost.

Research on biodegradable and safe solvents, the so-called "green" solvents, has gained importance in academia and industry (Carré et al., 2018). Ethanol stands out within this group, a solvent obtained biotechnologically that does not generate toxic waste or affect health and cheap to recover (Derkyi et al., 2011). Capello et al. (2007) carried out a comparison of 26 organic solvents by means of Life Cycle Assessment (LCA) in order to evaluate the potential as a green solvent, reporting ethanol as one of the solvents with the lowest environmental negative impact, mainly in water and air hazard categories. In addition Jimenez-Gonzalez et al. (2004) defined ethanol as the solvent with the best life cycle profile (lowest energy consumption and emissions) within a list of 47 solvents contained in the GSK Solvent Guide.

The solubility of vegetable oils (including rapeseed oil) in ethanol was studied in previous decades (Rao and Arnold, 1956). Franco et al. (2009) describe the ethanol as alternative solvent to hexane for the chilean hazelnut oil extraction. In addition, the extraction of soybean oil using different proportions of ethanol/water as solvent was evaluated, obtaining a protein fraction and an oil fraction (Sawada et al., 2014). Baümler et al. (2016) reported the extraction of oil-insoluble compounds such as sugars, among others, in the extraction with ethanol of sunflower oil from collet and Toda et al. (2016) analyzed the kinetics of soybean oil extraction using ethanol-water mixtures as solvents reporting an increase in kinetics parameters with temperature and dehydration level of solvent. Recently, Citeau et al. (2018) studied the extraction of oil from rapeseed flakes using ethanol at high pressure and temperatures, registers high yields. On the other hand Sánchez et al. (2018a) reported an increase in canolol content of canola oil extracted with ethanol with respect to hexane.

On the other hand, Chemat et al. (2012) established the reduction of energy consumption with respect to a conventional process as one of the principles to define a green extraction process. In this context, microwave technology presents an efficient alternative in the processing prior to extraction, with lower energy consumption with respect to hydrothermal treatments. Ramos et al. (2017) and Sánchez et al. (2017) studied the influence of microwave pretreatments on oil yield with hexane extraction and the quality of the obtained oils, observing an increase in the porosity of the extracted sample and higher yields for extraction times below $4 \mathrm{~h}$. Sánchez et al. (2018a) also studied the influence of microwave pretreatment on quality of extracted fraction with ethanol from canola seeds reporting an increase of canolol content by effect of microwave. In addition Sánchez et al. (2017) applied a bidimensional Fick's diffusion model to describe the kinetics of canola oil extraction; and Sánchez et al. (2018b) used an artificial neural network to model this process for different variety of canola seeds and pretreatments applied to these materials. However, the influence of the microwave pretreatment, kinetics and the phenomena involved in the oil extraction with ethanol has not yet been studied. The aim of this work was to study the kinetics of the canola oil extraction with ethanol, the influence of the microwave pretreatment and the phenomena involved in the extraction process.

\section{Material and methods}

\subsection{Materials}

The same batch seed $(10 \mathrm{~kg}$ of winter canola variety supplied by ALHIGH TECH S.R.L. (Argentina)) of canola used by Sánchez et al. (2018a, b) was used.

\subsection{Pretreatment}

The procedure described by Sánchez et al. (2017, 2018a) was followed. The samples were dried at a humidity of $5.7 \pm 0.2 \% \mathrm{db}$. in a forced convection oven at $35^{\circ} \mathrm{C}$ (drying oven DHG-9123A, China). A fraction was subjected to microwave irradiation for $5 \mathrm{~min}$ (BGH Quick Chef, model 36960, Argentina) at $607 \mathrm{~W}$, and then the untreated and treated samples were ground in a coffee grinder (Moulinex, Argentina) and sieved to obtain a particle size in the range of $0.42-1.00 \mathrm{~mm}$ for the different tests.

\subsection{Kinetics assays}

The oil extraction process (solid-liquid) was carried out in a batch device with a magnetic stirrer similar to that used by Fernández et al. (2012) and Sánchez et al. (2017) at different extraction times (300 to $64800 \mathrm{~s}$ ) and at $333 \mathrm{~K}$ (optimal temperature reported by Sawada et al. (2014) for the oil extraction from soybean) for both microwave-irradiated and untreated samples. In order to study the temperature dependence, for the unpretreated samples the extraction was also carried out at different times and at 313 and $323 \mathrm{~K}$. After the set time, the miscella was separated from the meal by centrifugation in a Thermo Scientific Sorvall Legend X1 (Germany) centrifuge at $14069 \mathrm{G}$ for $5 \mathrm{~min}$ and the supernatant was filtered, the micelle was collected in a flask and the solvent was evaporated in an R-3000 Büchi (Switzerland) rotary evaporator to obtain the total solventfree extract (SFE), which was washed with hexane $(20 \mathrm{ml})$ and filtered to cuantify oil fraction. The hexane was evaporated from the collected solution, obtaining the oil as hexane-soluble extract (HSE) (Sánchez et al., 2018a). Both fractions (SFE and HSE) were quantified gravimetrically, and the assays were performed in duplicate. The amount of oil 
obtained at $64800 \mathrm{~s}$ (mass of solute that diffuses at infinite time) was identified by $\mathrm{M} \infty$ (Perez et al., 2011; Fernández et al., 2012; Sánchez et al., 2017).

\subsection{Mathematical model}

A modified Fick's diffusion model at constant temperature (Eqs. (1) and (2)) and a bidimensional model (Sánchez et al., 2017) were used, where an Arrhenius-type temperature dependence of the diffusion coefficient is proposed, as shown in equation (3):

$$
\frac{\mathrm{M}_{t}}{\mathrm{M}_{\infty}}=1-\left(1-\frac{\mathrm{M}_{0}}{\mathrm{M}_{\infty}}\right) \sum_{n=1}^{8} \frac{6}{n^{2} \pi^{2}} e^{-n^{2} B\left(t-t_{0}\right)},
$$

where $\frac{\mathrm{M}_{0}}{\mathrm{M}_{0}}$ represents the average value of the oil extracted in the washing step, and $B$ is associated with the effective diffusivity $\left(\mathrm{D}_{\mathrm{eff}}, \mathrm{m}^{2} \mathrm{~s}^{-1}\right)$ :

$$
B=\frac{\mathrm{D}_{\mathrm{eff}} \cdot \pi^{2}}{R^{2}},
$$

with $R(\mathrm{~m})$ being the average particle radius. It is assumed that the particle size and shape remain constant during the extraction process.

$$
\begin{gathered}
\frac{\mathrm{M}_{t}}{\mathrm{M}_{\infty}}(t, T)=1-\left(1-\frac{\mathrm{M}_{0}}{\mathrm{M}_{\infty}}\right) \\
\sum_{n=1}^{8} \frac{6}{n^{2} \pi^{2}} e^{-n^{2}\left[\frac{\left(\mathrm{D}_{0} e^{-\frac{\Delta E}{\mathrm{R} T}}\right) \cdot \pi^{2}}{R^{2}}\right]\left(t-t_{0}\right)},
\end{gathered}
$$

where $t(\mathrm{~s})$ is the extraction time, $T(\mathrm{~K})$ is temperature, $\frac{\mathrm{M}_{0}}{\mathrm{M}_{\infty}}$ is the average value of the oil extracted in the washing step, $\mathrm{D}_{0}\left(\mathrm{~m}^{2} \mathrm{~s}^{-1}\right)$ is the pre-exponential constant, $\Delta E\left(\mathrm{kJmol}^{-1}\right)$ is the activation energy, $\mathrm{R}_{\mathrm{g}}$ is the gas constant $\left(\mathrm{kJmol}^{-1} \cdot \mathrm{K}^{-1}\right)$, and $R(\mathrm{~m})$ is the average particle radius.

The experimental data were fitted to the model using the Marquardt-Levenberg algorithm with the SIGMAPLOT software v. 11.0 (Software, 2008; de Figueiredo et al., 2019).

\subsection{Statistical analysis}

The obtained models for the yields of total SFE and HSE were compared by means of the extra sum of squares principle (ESS) to determine if there are any differences between the models for both yields. The proposed null hypothesis $\left(\mathrm{H}_{0}\right)$ and alternative hypothesis $\left(\mathrm{H}_{1}\right)$ are expressed by the following statements:

$\mathrm{H}_{0}$ : coefficients $\frac{\mathrm{M}_{0}}{\mathrm{M}_{\infty}}$ and/or $\mathrm{D}_{0}$ and/or $\Delta E$ do not depend on SFE or HSE (global model);

$\mathrm{H}_{1}$ : parameters $\frac{\mathrm{M}_{0}}{\mathrm{M}_{\infty}}, \mathrm{D}_{0}$ and $\Delta E$ depend on SFE and HSE (individual parameter model).

The contrast statistic $F_{0}$ was obtained from the ESS of each model, which allowed to compare the models associated with each one of the methods of comparison of the hypotheses with the help of contrast statistic Fc. The lack of fit was tested using a direct comparison method with contrast statistics $F_{0}$ dc (Fernández et al., 2012; Sánchez et al., 2017).

\subsection{Scanning electron microscopy (SEM)}

The micrographs of the samples were taken with a variable pressure scanning electron microscope (LEOEVO 40-XVP, England) at $15 \mathrm{kV}$. The pressure was varied from 40 to $70 \mathrm{~Pa}$.

\section{Results and discussion}

\subsection{Seed characterization}

The characterization of the raw material according to its proximate composition was carried out by Sánchez et al. (2017) and reported by Sánchez et al. (2018a) presenting a moisture content of $8.2 \pm 0.3$ percentage on dry basis $(\% \mathrm{db})$, $46.3 \pm 0.3 \% \mathrm{db}$ of oil, $24.9 \pm 0.8 \% \mathrm{db}$ of nitrogen-free extract, $20.3 \pm 0.1 \% \mathrm{db}$ of proteins, $5.0 \pm 0.1 \% \mathrm{db}$ of crude fiber, and $3.5 \pm 0.1 \% \mathrm{db}$ of ash.

\subsection{Kinetics of oil extraction}

Figure 1 shows the SFE and HSE yields at 313, 323 and $333 \mathrm{~K}$, and the oil yields obtained by Sánchez et al. (2017) using the same pool of unpretreated seeds and performing the extraction under the same conditions using hexane as the solvent.

The SFE yield was significantly higher than that of HSE for all times and temperatures (ANOVA, $p<0.05$ ). Since ethanol can extract compounds such as carbohydrates, proteins and phosphatides (Sawada et al., 2014; Baümler et al., 2016; Sánchez et al., 2018a, b), the difference between SFE and HSE can be attributed to these compounds. Baümler et al. (2016) obtained up to $9.98 \% \mathrm{db}$ of hexane-insoluble compounds (mostly consisting of sugars and phospholipids) from sunflower collets by Soxhlet extraction using ethanol $(95 \%)$ as solvent.

At a temperature of 313 and $323 \mathrm{~K}$, the oil yields extracted with hexane were significantly higher than the HSE fraction extracted with ethanol for all times, whereas at $333 \mathrm{~K}$ no significant differences were detected after $7200 \mathrm{~s}$.

\subsection{Model}

The analysis of the $F$ statistic by comparing the bidimensional model for the SFE and HSE yields showed that significant differences $(F=14.91, F \mathrm{c}=2.79)$ were detected between them. In fact, the $\Delta E$ value for SFE model was not significant ( $t$-test, $p>0.05$ ) showing no temperature dependence in the range of temperatures studied. Therefore, the bidimensional model was no suitable for SFE and modified Fick's diffusion model at constant temperature was adopted for SFE. The results are presented in Table 1. Regarding HSE yields, the adjustment results of bidimensional model is shown in Table 2 and Figure 2.

The analysis of $R^{2}$ adj and $p$ shows the correct model fit to the experimental data. In addition, the lack of fit analyzed with the $F$ statistic confirms the significance of the fit $\left(F_{0}=2.33 ; F_{\mathrm{c}}=3.05\right)$, likewise, all parameters were significant $(p<0.05)$. The washing fraction $\mathrm{M}_{0} / \mathrm{M}_{\infty}$ was lower than that obtained by hexane extraction (0.24; Sánchez et al., 2017), indicating the dependence of this parameter on the solvent used, with diffusion being the predominant phenom- 

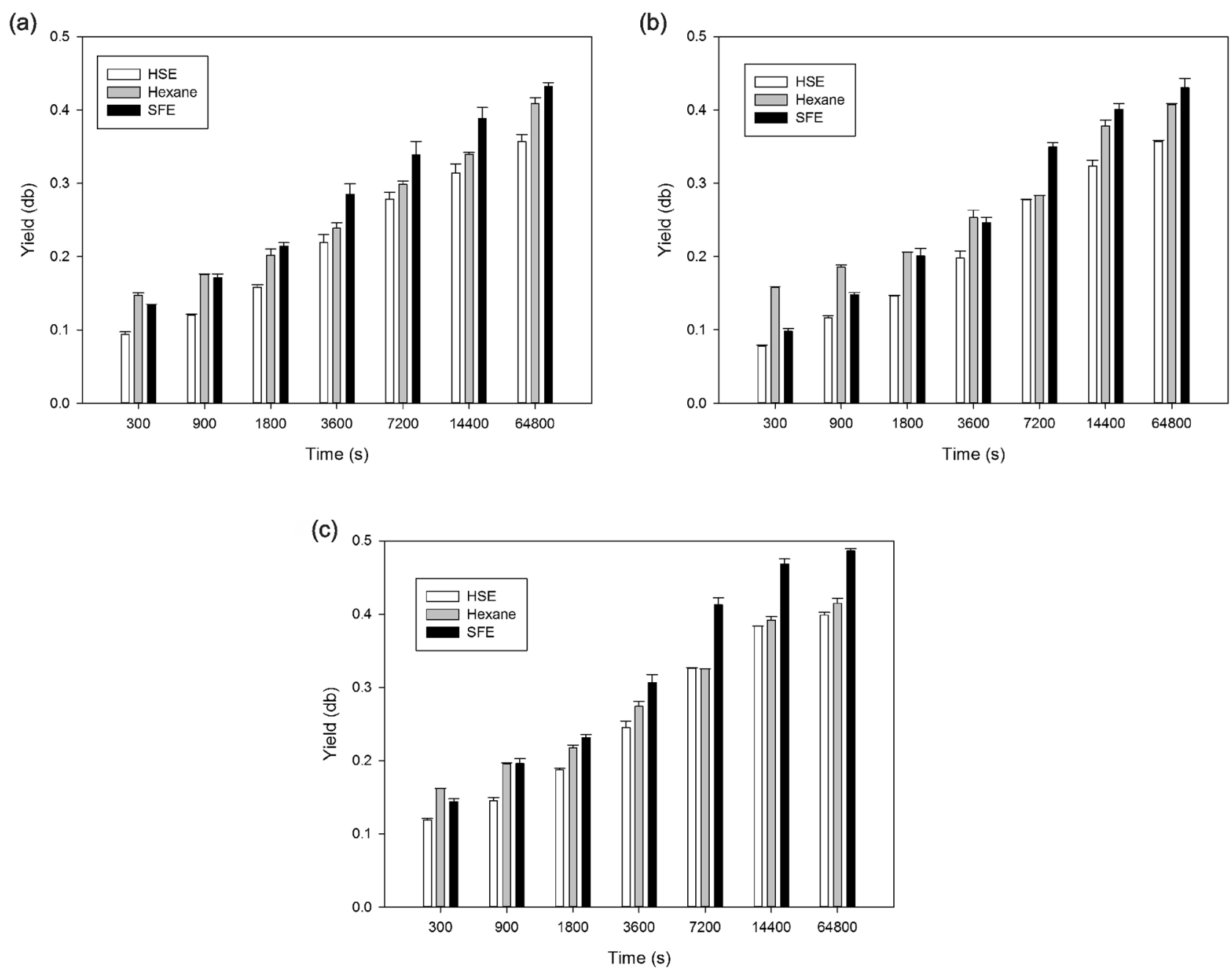

Fig. 1. Yield. a: $313 \mathrm{~K}$; b: $323 \mathrm{~K}$; c: 333 K. HSE: Hexane-soluble extract. Hexane: oil obtained by solvent extraction (hexane) (Sánchez et al., 2017). SFE: Total solvent-free extract.

Table 1. Coefficients of the time dependent modified Fick's model at constant temperature adjusted for SFE (total solvent-free extract).

\begin{tabular}{lll}
\hline & Value & $P$ value \\
\hline $\mathrm{M}_{0} / \mathrm{M}_{\infty}$ & $0.10 \pm 0.01$ & $<0.0001$ \\
$\mathrm{D}_{\text {eff }}\left(\mathrm{m}^{2} \mathrm{~s}^{-1}\right) \times 10^{12}$ & $1.28 \pm 0.09$ & $<0.0001$ \\
$R_{\text {adj }}^{2}$ & 0.99 & \\
$p$ model & $<0.0001$ & \\
\hline
\end{tabular}

SFE: Total solvent-free extract.

enon in ethanol extraction. The $\mathrm{D}_{0}$ and $\Delta E$ values were lower than that found for hexane extraction $\left(3.10 \times 10^{-9} \mathrm{~m}^{2} \mathrm{~s}^{-1}\right.$ and $21.37 \mathrm{kJmol}^{-1}$, respectively; Sánchez et al., 2017), showing the dependence of both values with the solvent. In addition, experimental $D_{\text {eff }}$ values were obtained by adjusting the data to the model at constant temperature (Eqs. (1) and (2)). For both temperatures, the model at constant temperature presented values of $R^{2}$ adj $=0.99$ and $p<0.0001$. The results are shown in Table 3.
The diffusion coefficients were higher than those obtained for hexane extraction (1.11-1.30.10 $0^{-12} \mathrm{~m}^{2} \mathrm{~s}^{-1}$ (Sánchez et al., 2017), showing the influence of the solvent on the kinetic parameters.

In comparison with hexane, the use of ethanol as a solvent negatively influenced the pre-exponential coefficient, probably due to the lower solubity of oil in ethanol than in hexane. However, ethanol positively influenced the extraction, lowering the activation energy value, which it can be attributed to a differential phenomenon in the extraction mechanism that allows increasing mass transfer (Fillion et al., 2002). Given that the values of $D_{\text {eff }}$ were higher than those obtained with hexane, it is concluded that the effect on the activation energy predominates over the effect on the preexponential coefficient.

\subsection{Microwave pretreatment effect}

No significant effect of the microwave pretreatment was observed on the SFE or HSE yields for all times at $333 \mathrm{~K}$. On the other hand, the HSE yields obtained by ethanol extraction were lower than the oil yields obtained by hexane extraction 
Table 2. Coefficients of the time and temperature dependent bidimensional model adjusted for HSE (hexane-soluble extract).

\begin{tabular}{lll}
\hline & Value & $P$ value \\
\hline $\mathrm{M}_{0} / \mathrm{M}_{\infty}$ & $0.17 \pm 0.02$ & $<0.0001$ \\
$\mathrm{D}_{0} \times 10^{12}\left(\mathrm{~m}^{2} \mathrm{~s}^{-1}\right)$ & $1.58 \pm 0.13$ & $<0.0001$ \\
$\Delta \mathrm{E}\left(\mathrm{kJmol}^{-1}\right)$ & $15.05 \pm 4.81$ & 0.0059 \\
$R_{\text {adj }}^{2}$ & 0.99 & \\
$p$ model & $<0.0001$ & \\
\hline
\end{tabular}

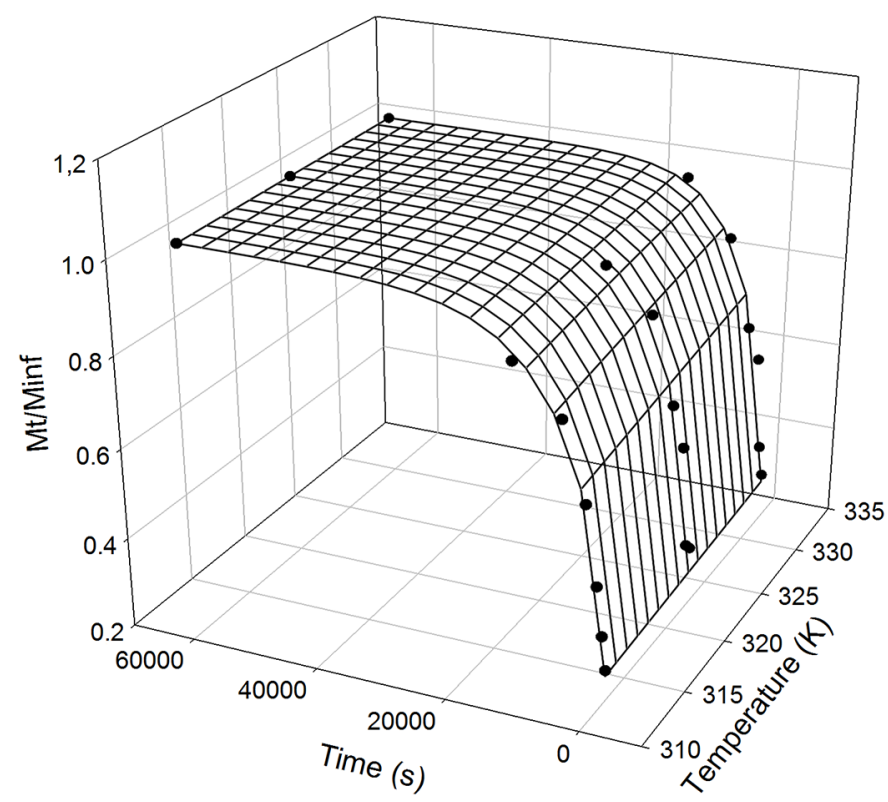

Fig. 2. Relative yields of hexane-soluble extract (HSE) and adjusted surface $\left(R_{\text {adj }}^{2}=0.99 ; p=<0.0001\right)$.

from microwave-pretreated samples (Sánchez et al., 2017), which could be attributed to the difference in the extraction capacity of the solvents. Table 4 presents a comparison between the extraction yield of oil/HSE for microwavepretreated and untreated samples using hexane, with a solvent: sample ratio of 1:17, and using ethanol at 1:17 and 1:34 ratios at different extraction times.

No effect of the microwave treatment was observed on the HSE yield for any of the different solid:solvent ratios using ethanol. At $14400 \mathrm{~s}$ no significant differences were detected for any of the analyzed assays. The obtained value could correspond to the total obtainable extract for the seed and system used, because they correspond to the maximum value reported by the literature for this seed and system (Sánchez et al., 2017). At $3600 \mathrm{~s}$, the yield for the 1:34 ratio with ethanol was not significantly different from that obtained from the pretreated samples using hexane, and these in turn were higher than the yields obtained with hexane from untreated samples and those obtained using ethanol with a 1:17 ratio. This indicates that for the ethanol extractions the decrement in the solid:solvent ratio (for ratios lower than 1:17) increases the extraction capacity, whereas in the case of canola oil extractions with hexane, no increase was detected in the
Table 3. Effective diffusion coefficients $\left(D_{\text {eff }}\right)$.

\begin{tabular}{llll}
\hline $\mathrm{D}_{\text {eff }} \times 10^{11}\left(\mathrm{~m}^{2} \mathrm{~s}^{-1}\right)$ & & & \\
\hline Temperature $(\mathrm{K})$ & 313 & 323 & 333 \\
HSE & $9.19 \pm 0.77$ & $10.85 \pm 0.19$ & $12.77 \pm 0.16$ \\
\hline
\end{tabular}

HSE: Hexane-soluble extract.

Table 4. Extraction yield of oil/HSE of canola seeds processed differently (samples), using two solid:solvent ratios at $333 \mathrm{~K}$.

\begin{tabular}{llll}
\hline $\begin{array}{l}\text { Relación } \\
\text { sólid:solvent }\end{array}$ & $\begin{array}{l}\text { Sample } \\
\text { (pretreatment-solvent) }\end{array}$ & \multicolumn{2}{c}{ Time (s) } \\
\hline & & 3600 & 14400 \\
& Untreated-hexane $^{*}$ & $0.274 \mathrm{a} \pm 0.007$ & $0.392 \mathrm{a} \pm 0.005$ \\
$1: 17$ & Microwave-hexane ${ }^{*}$ & $0.349 \mathrm{~b} \pm 0.005$ & $0.401 \mathrm{a} \pm 0.006$ \\
& Untreated-ethanol & $0.245 \mathrm{a} \pm 0.009$ & $0.383 \mathrm{a} \pm 0.001$ \\
& Microwave-ethanol & $0.244 \mathrm{a} \pm 0.009$ & $0.387 \mathrm{a} \pm 0.014$ \\
$1: 34$ & Untreated-ethanol & $0.358 \mathrm{~b} \pm 0.013$ & $0.387 \mathrm{a} \pm 0.007$ \\
& Microwave-ethanol & $0.355 \mathrm{~b} \pm 0.014$ & $0.388 \mathrm{a} \pm 0.005$
\end{tabular}

a,b: Indicators of Tukey's test $(p \leq 0.05)$ for significant differences detection. Different letters in the same column indicate significant differences.

* Sánchez et al. (2017).

extraction capacity for ratios lower than 1:10 (Thobani and Diosady, 1997). These results show that using an adequate solid:solvent ratio for the extraction with ethanol can allow to obtain yields equivalent to those obtained with hexane from microwave-pretreated samples, without the need to apply any microwave pretreatment. It should be noted that higher SFE yields were observed for both analyzed times $(0.443 \pm 0.141 \mathrm{db}$ at $3600 \mathrm{~s}$ and $0.491 \pm 0.001 \mathrm{db}$ at $14400 \mathrm{~s}$ ) with decreasing solid:solvent ratios; however, no significant differences were detected due to the microwave pretreatment.

\subsection{Scanning electron micrographs of ground seeds before and after extraction}

SEM images of ground seeds before and after oil extraction with different solvents (hexane and ethanol) are shown in Figure 3.

In the case of the pre-extraction samples (Figs. 3A and 3D), a defined structural matrix can be observed, which is more compact in the sample without pretreatment. Figure 3E shows a more open structure than Figure $3 \mathrm{~B}$, and clearer than those exhibited in Figures 3A and 3D. However, in the postextraction samples with ethanol (Figs. 3C and 3D), a loss of structural integrity can be observed due to the effect of ethanol, in contrast to what is observed in the post-extraction samples with hexane.

Hydrophobic solvents such as hexane present difficulties for the oil extraction from oil bodies surrounded by their membranes (Huang, 1992), requiring thermal and/or mechanical pretreatments to break the microstructure of the seeds and the oil bodies. Ramos et al. (2017) and Sánchez et al. (2017) reported an increase in extraction yields with hexane by applying a 

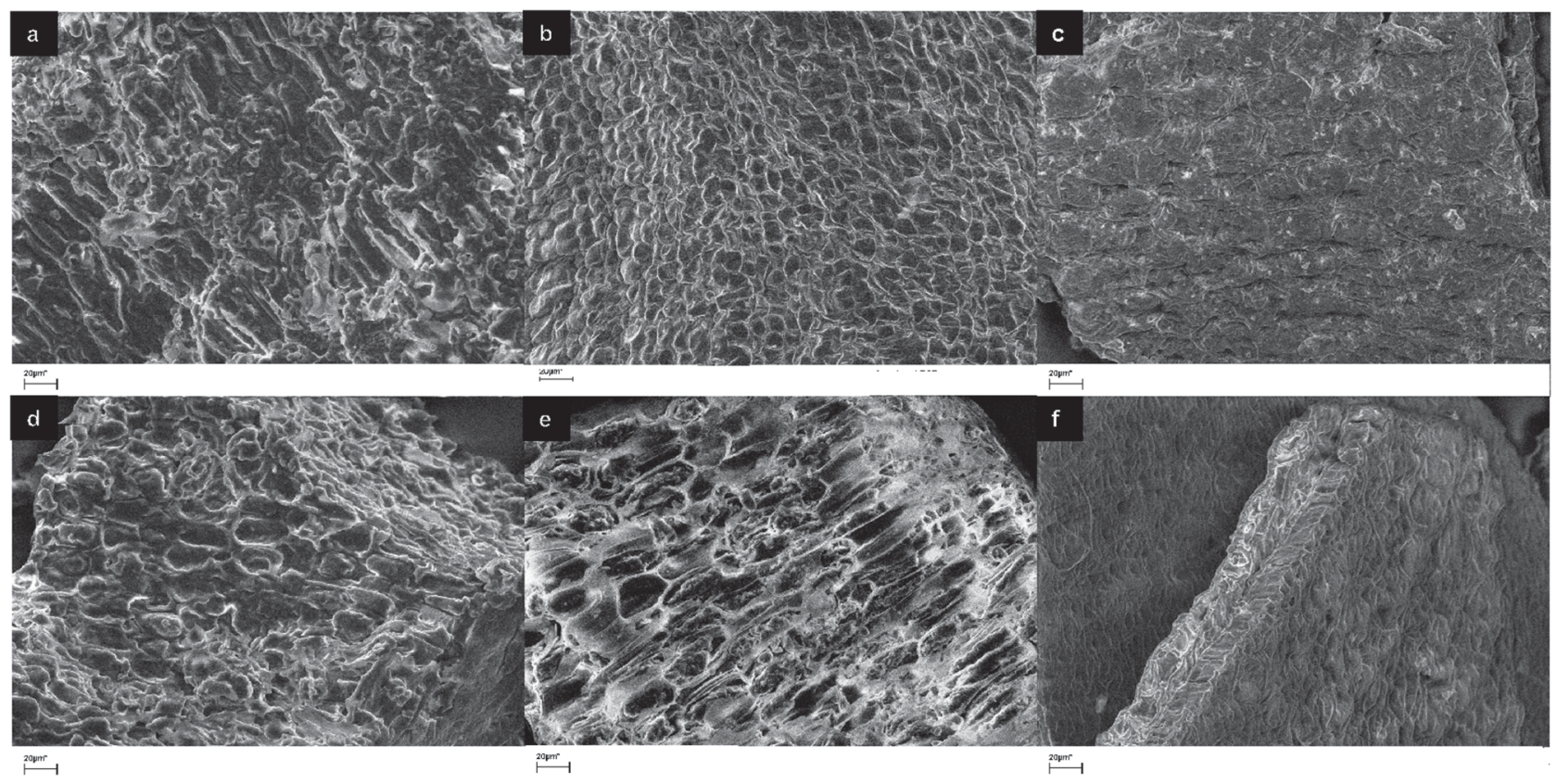

Fig. 3. Scanning electron micrographs of ground seeds. a: before extraction; b: after extraction with hexane; c: after extraction with ethanol; d: microwave-pretreated ground seeds before extraction; e: microwave-pretreated and ground seeds after extraction with hexane; f: microwavepretreated and ground seeds after extraction with ethanol.

microwave pretreatment, with the increase being attributed to the rupture of cell structures and increased porosity, allowing greater accessibility to the oil of the solvent. On the other hand, ethanol is a polar solvent capable of dissolving compounds such as phosphatides and carbohydrates, and oleosin structures with polar aminoacids such as proline, which are part of the membranes of plant cells and particularly those covering oil bodies (Huang, 1992). Thus in the oil extraction with ethanol, a phenomenon of partial dilution of the structures could be predominant, as it was observed in the SEM images, facilitating the accessibility of the solvent to the oil, regardless of the breakage of the structures by the effect of the pretreatment could explain the lower value of activation energy with respect to extraction with hexane.

\section{Conclusions}

The extraction with ethanol allowed to obtain a total extract (SFE) from which an oil fraction was obtained by washing with hexane (HSE) and a hexane-insoluble fraction consisting of phosphatides, carbohydrates and proteins soluble in ethanol. The oil yields at $333 \mathrm{~K}$ and after $7200 \mathrm{~s}$ of extraction were not significantly different from those obtained with hexane; at lower extraction times and temperatures, the yields obtained with hexane were higher than those obtained with ethanol. A bidimensional modified Fick's diffusion global model $\left(R_{\text {adj }}^{2}=\right.$ 0.99) was used to adjust the HSE extraction yields. The washing fraction $\mathrm{M}_{0} / \mathrm{M}_{\infty}$ presented a value of 0.03 , lower than that obtained by hexane extraction; however the diffusion coefficients were two order higher than those obtained with hexane, with diffusion being the predominant phenomenon in the extraction with ethanol and showing an influence of the solvent on the kinetic parameters.
No significant effect of the microwave-pretreatment was detected on the yield of either SFE or HSE at $333 \mathrm{~K}$. However, when the solid:solvent ratio decreased, an increase in those yields was observed, achieving similar values to those obtained for microwave-pretreated samples and extracted with hexane. The comparison of SEM images of seeds before extraction, after extraction with ethanol and after extraction with hexane showed a dilution of the structural matrix when using ethanol as extraction solvent, whereas in the samples extracted with hexane the solvent did not seem to have an effect on the structural matrix. This indicated the importance of the microwave pretreatment in breaking the structures and the greater accessibility of the oil in hexane extraction, but its effect was not evident in the extraction with ethanol.

\section{Nomenclature}

NFE

Carbohydrate content as nitrogen free extract (\% dry basis)

SFE

HSE

$\mathrm{M}_{0} / \mathrm{M}_{\infty}$

$\mathrm{D}_{\text {eff }}$

$\mathrm{D}_{0}$

$F_{0}$

$F_{\mathrm{c}}$ Total solvent-free extract (dry basis) Hexane-soluble extract (dry basis) Model-fitting parameters (dimensionless) Effective diffusion coefficients $\left(\mathrm{m}^{2} \mathrm{~s}^{-1}\right)$ Pre-exponential constant $\left(\mathrm{m}^{2} \mathrm{~s}^{-1}\right)$ Contrast statistic for parameter comparison

Critical value of Snedecor's $F$ distribution for the comparison of the parameters

\section{M} Mass of solute that diffuses $(\mathrm{kg}$ solute $\mathrm{kg}$ dry meal ${ }^{-1}$ )

$R$ Average particle radius of extreme values (m) 


$\begin{array}{ll}\mathrm{R}_{\mathrm{g}} & \text { Gas constant }\left(\mathrm{kJ} \mathrm{mol}^{-1} \mathrm{~K}^{-1}\right) \\ t & \text { Diffusion time }(\mathrm{s}) \\ T & \text { Absolute temperature }(\mathrm{K}) \\ \Delta E & \text { Activation energy }\left(\mathrm{kJ} \mathrm{mol}^{-1}\right)\end{array}$

\section{Subscripts}

$\begin{array}{ll}0,1,2, \ldots ., n & \text { Series terms } \\ 0 & \text { Washing stage } \\ \infty & \text { Infinite time } \\ t & \text { At time } t\end{array}$

Acknowledgments. The authors acknowledge AL HIGH TECH S.R.L. (Argentina) for donating the raw material and the support of ANPCyT (Agencia Nacional de Promoción Científica y Tecnologica) and Facultad de Ingeniería, Universidad Nacional del Centro de la Provincia de Buenos Aires, Argentina.

Conflict of interest. The authors declare that they have no conflicts of interest in relation to this article.

\section{References}

Baümler E, Carrín M, Carelli A. 2016. Extraction of sunflower oil using ethanol as solvent. J Food Eng 178: 190-97.

Capello C, Fischer U, Hungerbühler K. 2007. What is a green solvent? A comprehensive framework for the environmental assessment of solvents. Green Chem 9(9): 927-934.

Carré P, Citeau M, Dauguet S. 2018. Hot ethanol extraction: Economic feasibility of a new and green process. OCL 25(2): D206.

Chemat F, Vian M, Cravotto G. 2012. Green extraction of natural products: Concept and principles. Int J Mol Sci 13(7): 8615-8627.

Citeau M, Slabi S, Joffre F, Carré P. 2018. Improved rapeseed oil extraction yield and quality via cold separation of ethanol miscella. OCL 25(2): D207.

de Figueiredo A, Fernández M, Nolasco S. 2019. Extraction of high stearic high oleic sunflower oil (hsho): Effect of dehulling and hydrothermal pretreatment. J Food Eng 240: 49-55.

Derkyi N, Adu-Amankwa B, Sekyere D, Darkwa N. 2011. Optimum acetone and ethanol extraction of polyphenols from pinus caribaea bark: Maximizing tannin content using response surface methodology. Chem Prod Process Model 6(1): 1-24.

Fernández M, Perez E, Crapiste G, Nolasco S. 2012. Kinetic study of canola oil and tocopherol extraction: Parameter comparison of nonlinear models. J Food Eng 111(4): 682-89.

Fillion B, Morsi B, Heier K, Machado R. 2002. Kinetics, gas-liquid mass transfer, and modeling of the soybean oil hydrogenation process. Ind Eng Chem Res 41(4): 697-709.

Franco D, Sineiro J, Núñez M. 2009. Analysis of variables and modeling of gevuina avellana oil extraction with ethanol near azeotrope conditions. J Food Process Eng 32(5): 664-81.
Huang A. 1992. Oil bodies and oleosins in seeds. Annu Rev Plant Biol 43(1): 177-200.

Jimenez-Gonzalez C, Curzons A, Constable D, Cunningham V. 2004. Expanding GSK's solvent selection guide-Application of life cycle assessment to enhance solvent selections. Clean Tech Environ Policy 7(1): 42-50.

Koski A, Pekkarinen S, Hopia A, Wähälä K, Heinonen M. 2003. Processing of rapeseed oil: Effects on sinapic acid derivative content and oxidative stability. Eur Food Res Tech 217(2): 110-14.

Kozlowska H, Naczk M, Shahidi F, Zadernowski R. Phenolic acids and tannins in rapeseed and canola. In : Shahidi F, (ed). Canola and rapeseed. USA: Springer, 1990, pp. 193-210.

Perez E, Carelli A, Crapiste G. 2011. Temperature-dependent diffusion coefficient of oil from different sunflower seeds during extraction with hexane. J Food Eng 105(1): 180-85.

Ramos L, Sánchez R, De Figueiredo A, Nolasco S, Fernández M. 2017. Optimization of microwave pretreatment variables for canola oil extraction. J Food Process Eng 40(3): e12431-n/a.

Rao RK, Arnold L. 1956. Alcoholic extraction of vegetable oils. III. solubilities of babassu, coconut, olive, palm, rapeseed, and sunflower seed oils in aqueous ethanol. J Am Oil Chem Soc 33(9): 389-91.

Sánchez R, Mateo C, Fernández M, Nolasco S. 2017. Bidimensional modeling applied to oil extraction kinetics of microwavepretreated canola seeds. J Food Eng 192: 28-35.

Sánchez R, Fernández M, Nolasco S. 2018a. Hexane-free green solvent extraction of canola oil from microwave-pretreated seeds and of antioxidant-rich byproducts. Eur J Lipid Sci Tech 120(9): 1800209.

Sánchez R, Fernández M, Nolasco M. 2018b. Artificial neural network model for the kinetics of canola oil extraction for different seed samples and pretreatments. J Food Process Eng 41 (1): e12608.

Sawada M, Lopes Venâncio L, Toda T, Rodrigues C. 2014. Effects of different alcoholic extraction conditions on soybean oil yield, fatty acid composition and protein solubility of defatted meal. Food Res Int 62: 662-70.

Sicaire A, Vian M, Fine F, Joffre F, Carré P, Tostain S, Chemat F. 2015. Alternative bio-based solvents for extraction of fat and oils: Solubility prediction, global yield, extraction kinetics, chemical composition and cost of manufacturing. Int J Mol Sci 16(4): $8430-53$.

Software, Systat. Sigmaplot for Windows, Version 11.0. 2008. Systat Software Inc., San Jose, California.

Thobani M, Diosady L. 1997. Two-phase solvent extraction of canola. J Am Oil Chem Soc 74(3): 207-14.

Toda T, Sawada M, Rodrigues C. 2016. Kinetics of soybean oil extraction using ethanol as solvent: Experimental data and modeling. Food Bioprod Process 98: 1-10.

Wakamatsu D, Morimura S, Sawa T, Kida K, Nakai C, Maeda H. 2005. Isolation, identification, and structure of a potent alkylperoxyl radical scavenger in crude canola oil, canolol. Biosci Biotech Biochem 69(8): 1568-74.

Cite this article as: Sánchez RJ, Fernández MB, Nolasco SM. 2019. Ethanol extraction of canola oil: Kinetics and effects of type of solvent and microwave-pretreatment. OCL 26: 27. 